\title{
Service load analysis of unbonded partially prestressed concrete members
}

\author{
F. T. K. Au, ${ }^{*}$ J. S. Du, ${ }^{\dagger}$ and Y. K. Cheung* \\ The University of Hong Kong; Beijing Jiaotong University
}

In the design of unbonded partially prestressed concrete (UPPC) members, it is necessary to estimate the stresses in steel and concrete in order to satisfy the requirements of the serviceability limit state. A numerical method has been developed to predict the response of UPPC beams under service load, and the results agree well with experimental results reported in the technical literature. A parametric study has been undertaken to evaluate the variation of stress in prestressed steel under service load as well as the ratio of length of equivalent deformation region to the neutral axis depth at critical section. Results show that this ratio is not sensitive to the variation of the combined reinforcement index. From the moment of application of load to the cracking of the beam, and until the yielding of nonprestressed steel, this ratio is fairly stable and it can be taken as a constant. With the determination of this ratio, an approximate cubic equation similar to that used for cracked section analysis of bonded partially prestressed members is established. Predictions of stresses under service load are in good agreement with available test data.

\section{$A_{\mathrm{p}}, A_{\mathrm{s}}$ \\ $A_{0}, A_{0 \mathrm{k}}$ \\ $b, b_{\mathrm{w}}$ \\ $c$ \\ $c_{\mathrm{k}}^{\mathrm{i}}$ \\ $\boldsymbol{C}_{1}, \boldsymbol{C}_{2}$ \\ $d_{\mathrm{p}}, d_{\mathrm{s}}$ \\ $E_{\mathrm{c}}$ \\ $E_{\mathrm{p}}, E_{\mathrm{s}}$ \\ $e, e_{k}$}

Notation

cross-sectional areas of prestressed and non-prestressed steel respectively

$e_{0}$
$\boldsymbol{F}$ decompression

$\boldsymbol{f}_{\mathrm{c}} \quad$ concrete stress in top fibre under service

load

$\boldsymbol{f}_{\mathrm{c}}^{\prime} \quad$ cylinder compressive strength of concrete

$\boldsymbol{f}_{\mathrm{p}} \quad$ stress in prestressed steel under service load

$\boldsymbol{f}_{\mathrm{pe}} \quad$ effective prestress in prestressed tendon

$\boldsymbol{f}_{\mathrm{pe}}(i) \quad$ stress in prestressed steel at loading step $i$

$\boldsymbol{f}_{\mathrm{ps}} \quad$ ultimate stress in prestressed steel at failure of member

$\boldsymbol{f}_{\mathrm{py}}, \boldsymbol{f}_{\mathrm{pu}} \quad$ yield and ultimate stresses of prestressed steel respectively

$\Delta \boldsymbol{f}_{\mathrm{p}} \quad$ increase in tendon stress

$\boldsymbol{f}_{\mathrm{r}} \quad$ modulus of rupture of concrete

$\boldsymbol{f}_{\mathrm{s}} \quad$ stress in non-prestressed steel under service load

$\boldsymbol{f}_{\mathrm{y}} \quad$ yield stress of non-prestressed steel

$h, h_{\mathrm{f}} \quad$ height of cross-section and thickness of flange respectively

$h_{1}, h_{2} \quad$ distances from action line of $\boldsymbol{C}_{1}$ and $\boldsymbol{C}_{2}$ to the top fibre respectively

$\boldsymbol{I}_{0}, \boldsymbol{I}_{0 k} \quad$ transformed sectional moment of inertia and that of element $k$ respectively

* Department of Civil Engineering, The University of Hong Kong, Pokfulam Road, Hong Kong, P.R. China.

$\dagger$ College of Civil Engineering, Beijing Jiaotong University, Beijing, 100044, P.R. China.

(MCR 41256) Paper received 10 March 2004; last revised 30 June 2004; accepted 16 August 2004 moment of inertia of cracked section

$\begin{array}{ll}\boldsymbol{I}_{\mathrm{cr}} & \text { moment of inertia of cracked section } \\ \boldsymbol{I}_{\mathrm{g}} & \text { gross moment of inertia of section } \\ L & \text { distance between end anchorages } \\ L_{0} & \text { distance between two point loads } \\ L_{\mathrm{e}} & \text { length of equivalent deformation region } \\ L_{\mathrm{n}} & \text { span length of beam }\end{array}$




\begin{tabular}{|c|c|}
\hline$M$ & total applied moment \\
\hline $\boldsymbol{M}_{\mathrm{cr}}$ & cracking moment \\
\hline $\boldsymbol{M}_{k, \mathrm{cr}}$ & cracking moment of element $k$ \\
\hline $\boldsymbol{M}_{\mathrm{k}}^{\mathrm{i}}$ & $\begin{array}{l}\text { applied moment in element } k \text { at loading } \\
\text { step } i\end{array}$ \\
\hline $\boldsymbol{M}_{\mathrm{u}}$ & ultimate flexural moment of member \\
\hline$m$ & $\begin{array}{l}\text { total number of elements in numerical } \\
\text { analysis }\end{array}$ \\
\hline $\boldsymbol{P}_{0}, \boldsymbol{P}_{i}$ & $\begin{array}{l}\text { effective prestressing force before loading } \\
\text { and at loading step } i \text { respectively }\end{array}$ \\
\hline$q_{0}$ & combined reinforcement index \\
\hline $\boldsymbol{R}$ & resultant force \\
\hline $\boldsymbol{T}_{\mathrm{p}}, \boldsymbol{T}_{\mathrm{s}}$ & $\begin{array}{l}\text { tensions in prestressed and non-prestressed } \\
\text { steel, respectively, under service load }\end{array}$ \\
\hline$\Delta T_{\mathrm{p}}, \Delta \boldsymbol{T}_{\mathrm{s}}$ & $\begin{array}{l}\text { increases in tension in prestressed and } \\
\text { non-prestressed steel respectively }\end{array}$ \\
\hline$y_{\mathrm{k}}^{\mathrm{b}}, y_{\mathrm{k}}^{\mathrm{t}}$ & $\begin{array}{l}\text { distances from the centroidal axis of the } \\
\text { transformed section to the bottom and top } \\
\text { fibres of cross-section in element } k\end{array}$ \\
\hline $\bar{y}$ & $\begin{array}{l}\text { depth from top fibre to centroid of cracked } \\
\text { section }\end{array}$ \\
\hline$\Delta \varepsilon$ & $\begin{array}{l}\text { 'fictitious' increase in strain above } \\
\text { decompressive strain in concrete at the } \\
\text { level of prestressing tendons }\end{array}$ \\
\hline$\varepsilon_{\mathrm{c}}$ & $\begin{array}{l}\text { concrete compressive strain in the top } \\
\text { fibre }\end{array}$ \\
\hline $\boldsymbol{\varepsilon}_{\mathrm{ce}}$ & $\begin{array}{l}\text { precompressive strain in concrete at the } \\
\text { level of prestressing tendons }\end{array}$ \\
\hline $\boldsymbol{\varepsilon}_{\mathrm{cu}}$ & $\begin{array}{l}\text { ultimate concrete compressive strain in top } \\
\text { fibre and is taken as } 0.003 \text {. }\end{array}$ \\
\hline $\boldsymbol{\varepsilon}_{\mathrm{k}}^{\mathrm{b}, \mathrm{i}}, \boldsymbol{\varepsilon}_{\mathrm{k}}^{\mathrm{t}, \mathrm{i}}$ & $\begin{array}{l}\text { concrete strains in the bottom and top } \\
\text { fibres of element } k \text { at loading step } i\end{array}$ \\
\hline $\boldsymbol{\varepsilon}_{\mathrm{p}}, \boldsymbol{\varepsilon}_{\mathrm{s}}$ & $\begin{array}{l}\text { strains in prestressed and non-prestressed } \\
\text { steel respectively }\end{array}$ \\
\hline $\boldsymbol{\varepsilon}_{\mathrm{pe}}$ & effective prestrain of prestressing tendons \\
\hline$\varepsilon_{\mathrm{pu}}$ & ultimate strain of prestressed steel \\
\hline$\lambda, \lambda_{i}$ & $\begin{array}{l}\text { ratio of length of equivalent deformation } \\
\text { region } L_{\mathrm{e}} \text { to the neutral axis depth } c \text { at } \\
\text { critical section, and that at loading step } i \\
\text { respectively }\end{array}$ \\
\hline$\lambda_{\mathrm{av}}$ & $\begin{array}{l}\text { average of all } \lambda_{i} \text { obtained at each loading } \\
\text { step from the cracking of the beam to the } \\
\text { yielding of non-prestressed steel }\end{array}$ \\
\hline$\lambda_{10}$ & $\begin{array}{l}\text { ratio of length of equivalent deformation } \\
\text { region } L_{\mathrm{e}} \text { to the neutral axis depth } c \text { at } \\
\text { critical section for members with span- } \\
\text { depth ratio equal to } 10\end{array}$ \\
\hline $\boldsymbol{\sigma}_{\mathrm{c}}$ & stress of concrete \\
\hline$\sigma_{\mathrm{ps}}, \boldsymbol{\sigma}_{\mathrm{s}}$ & $\begin{array}{l}\text { stresses of prestressed and non-prestressed } \\
\text { steel respectively }\end{array}$ \\
\hline$\Omega, \Omega_{\mathrm{cr}}$ & $\begin{array}{l}\text { bond reduction coefficient at uncracked } \\
\text { and cracked states respectively }\end{array}$ \\
\hline
\end{tabular}

\section{Introduction}

Partial prestressing as defined by the Joint ACIASCE Committee $423^{1}$ is 'an approach in design and construction in which prestressed reinforcement or a combination of prestressed and non-prestressed reinforcement is used such that tension and cracking in concrete due to flexure are allowed under service dead and live loads, while serviceability and strength requirements are satisfied.' Compared with fully prestressed concrete structures, adoption of partial prestressing may result in increased ductility and energy absorption capability, improved economy, as well as reduction of the camber and creep deformation due to prestress. The use of unbonded tendons not only leads to economical and simple designs, but also enables fast installation and easy replacement of defective tendons. The unbonded tendons can also provide an economic solution for strengthening and repairing existing structures. Tests have shown that fully prestressed concrete beams with unbonded tendons and without non-prestressed steel behave as shallow tied arches after cracking rather than as flexural members. As the load increases, only one or two wide cracks develop and propagate towards the compression zone of the members, and the failure of specimen is brittle. However unbonded partially prestressed concrete (UPPC) beams normally develop cracks well distributed along their span under loading because of the presence of non-prestressed steel. The crack widths increase steadily as the load increases. The specimens behave as flexural members under overloads, rather than as tied arches. Therefore in practical use, unbonded prestressed concrete members usually contain some non-prestressed steel. ${ }^{2-6}$

Previous studies of unbonded prestressed and partially prestressed concrete members have mainly been on the ultimate limit state in bending, but very few have addressed the behaviour at service load conditions. ${ }^{7}$ As pointed out by Nilson for bonded partially prestressed concrete members, ${ }^{8}$ evaluation of the service stresses in UPPC members is also necessary for evaluation of stress compliance, crack widths, elastic and creep deflections, and fatigue effects at service load.

This paper describes a method for evaluation of service load stresses at cracked sections in UPPC members. A parametric study is also undertaken to evaluate the variation of stress in prestressed steel under service loads. The predicted responses are compared with available experimental results. To consider the influence of the relative slip between the unbonded tendon and its surrounding concrete under service load, the ratio of the length of equivalent deformation region to the neutral axis depth is studied. With the determination of this ratio, a cubic equation similar to that used for cracked section analysis of bonded partially prestressed members is established.

\section{Review of previous work}

Balaguru ${ }^{9}$ proposed a method to predict the stress changes of unbonded tendon for the complete loading

Magazine of Concrete Research, 2005, 57, No. 4 
range. The formula was developed using the basic theory of flexure to obtain the equation for the elastic curve, and numerical integration to obtain the curve lengths. Using the calculated results of the increase in tendon strain for various span lengths, eccentricities and maximum deflections, a regression equation was developed, which predicted the increase in tendon strains as a function of the span-eccentricity and eccentricity-maximum deflection ratios.

Naaman and Alkhairi ${ }^{10}$ later proposed a method for analysis of unbonded prestressed concrete members under service load using the bond reduction coefficient. The approach was essentially to reduce the beams with unbonded tendons to the equivalent case with bonded tendons through the use of a bond reduction coefficient. Thus the previous analytical solutions for beams prestressed or partially prestressed with bonded tendons could be used. The computation of bond reduction coefficients $\Omega$ before cracking from basic principles of mechanics is simple. Exact values of $\Omega$ derived ${ }^{10}$ for simply supported beams with different tendon profiles and different types of load applications are summarised in Table 1. However, the computation of 'exact' bond reduction coefficient $\Omega_{\text {cr }}$ in the cracked state for different types of loading and tendon profiles is a very difficult analytical task, and can be regarded as virtually impossible. ${ }^{5}$

For a simply supported beam with two symmetrically disposed point loads separated by a distance $L_{0}$, the following approximate expression of $\Omega_{\mathrm{cr}}$ was derived by Harajli and Kanj ${ }^{5}$

$$
\begin{aligned}
\Omega_{\mathrm{cr}}= & \Omega-0 \cdot 5\left(1-\frac{L_{0}}{L}\right) \\
& \times\left\{\frac{\boldsymbol{M}_{\mathrm{cr}}}{\boldsymbol{M}}-1 /\left[\left(\frac{\boldsymbol{M}}{\boldsymbol{M}_{\mathrm{cr}}}-1\right) \frac{\boldsymbol{I}_{\mathrm{g}}}{\boldsymbol{I}_{\mathrm{cr}}}+1\right]\right\}
\end{aligned}
$$

Table 1. Values of bond reduction coefficient $\Omega$ for uncracked state. $^{10}$

\begin{tabular}{l|l}
\hline Type of loading and tendon profile & $\begin{array}{l}\text { Bond reduction coefficient } \\
\text { (uncracked state) }\end{array}$ \\
\hline $\begin{array}{l}\text { Uniform load and straight tendons } \\
\text { Uniform load and parabolic tendons }\end{array}$ & $\Omega=2 / 3$ \\
$\Omega=8 / 15+(2 / 15)\left(e_{\mathrm{s}} / e_{\mathrm{c}}\right)$ \\
$\begin{array}{l}\text { Uniform load and harped tendons } \\
\text { Third-point load and straight }\end{array}$ & $\Omega=5 / 12+(1 / 4)\left(e_{\mathrm{s}} / e_{\mathrm{e}}\right)$ \\
tendons & $\Omega=2 / 3$ \\
$\begin{array}{l}\text { Third-point load and parabolic } \\
\text { tendons }\end{array}$ & $\Omega=44 / 81+(10 / 81)\left(e_{\mathrm{s}} / e_{\mathrm{c}}\right)$ \\
$\begin{array}{l}\text { Third-point load and harped tendons } \\
\text { Central-point load and straight }\end{array}$ & $\Omega=23 / 54+(13 / 54)\left(e_{\mathrm{s}} / e_{\mathrm{c}}\right)$ \\
tendons & $\Omega=1 / 2$ \\
$\begin{array}{l}\text { Central-point load and parabolic } \\
\text { tendons } \\
\text { Central-point load and harped } \\
\text { tendons }\end{array}$ & $\Omega=5 / 12+(1 / 12)\left(e_{\mathrm{s}} / e_{\mathrm{c}}\right)$ \\
\hline
\end{tabular}

Notes: $e_{\mathrm{S}}$ is eccentricity at end supports; $e_{\mathrm{c}}$ is eccentricity at midspan; positive below neutral axis. where the bond reduction coefficient $\Omega$ before cracking is given in Table $1, \boldsymbol{M}$ is the total applied moment, $\boldsymbol{M}_{\text {cr }}$ is the cracking moment, $\boldsymbol{I}_{\text {cr }}$ is the moment of inertia of the cracked section, $\boldsymbol{I}_{\mathrm{g}}$ is the gross section moment of inertia, and $L$ is the distance between the end anchorages. Harajli and $\mathrm{Kanj}^{4}$ analysed the variation of $\Omega_{\text {cr }}$ versus $\boldsymbol{M} / \boldsymbol{M}_{\mathrm{cr}}$ for beams with straight tendons for different ranges of $\boldsymbol{I}_{\mathrm{cr}} / \boldsymbol{I}_{\mathrm{g}}$, observed that $\Omega_{\mathrm{cr}}$ did not differ significantly from its value before cracking, and assumed $\Omega_{\mathrm{cr}}=\Omega$ for practical analysis of the cracked section. On the other hand, Naaman and Alkhairi ${ }^{10}$ suggested the following equation for $\Omega_{\mathrm{cr}}$

$$
\Omega_{\mathrm{cr}}=\Omega \frac{I_{\mathrm{cr}}}{I_{\mathrm{g}}}
$$

Obviously the major problem here lies in the estimation of the value of $\Omega_{\mathrm{cr}}$. Note that the neutral axis location for cracked prestressed concrete beams depends not only on the geometry of the cross-section and the material properties, but also on the prestressing force and the external loading. Therefore the exact value of $\boldsymbol{I}_{\text {cr }}$ in equations (1) and (2) is not known until the cracked section is analysed.

To account for the relative slip between the unbonded tendons and the surrounding concrete, and for the determination of ultimate tendon stress at flexural failure, Pannell ${ }^{11}$ introduced the coefficient $\lambda$, which is the ratio of length of equivalent deformation region $L_{\mathrm{e}}$ to the neutral axis depth $c$ at the critical section. He found that $\lambda$ was a constant value for unbonded prestressed concrete beams even for different span-depth ratios and suggested taking $\lambda$ as 10 for design purposes. Pannell's method subsequently formed the basis of the British Code BS $8110^{12}$ and the Canadian Code A23.3-94 ${ }^{13}$ for determination of the stress of an unbonded tendon at ultimate. After analysis of available test results obtained by different investigators, $\mathrm{Au}$ and $\mathrm{Du}^{14}$ concluded that Pannell's coefficient $\lambda$ could indeed be taken as a constant for unbonded prestressed concrete members at ultimate. This paper attempts to extend the use of coefficient $\lambda$ to the cracked section analysis of UPPC members under service load.

\section{Formulation of the problem}

It is assumed that the increase in tendon elongation between end anchorages and therefore the corresponding tendon stress increment is mainly due to the deformation within the equivalent deformation region of length $L_{\mathrm{e}}=\lambda \times c$. Consider a simply supported beam with cross-section as shown in Fig. 1(a) with flange width $b$, web width $b_{\mathrm{w}}$, height of section $h$ and thickness of flange $h_{\mathrm{f}}$. The prestressed steel of crosssectional area $A_{\mathrm{p}}$ and modulus of elasticity $E_{\mathrm{p}}$ is provided at a depth of $d_{\mathrm{p}}$. The non-prestressed steel of cross-sectional area $A_{\mathrm{s}}$, modulus of elasticity $E_{\mathrm{s}}$ and yield stress $\boldsymbol{f}_{\mathrm{y}}$ is provided at a depth of $d_{\mathrm{s}}$. Under the 


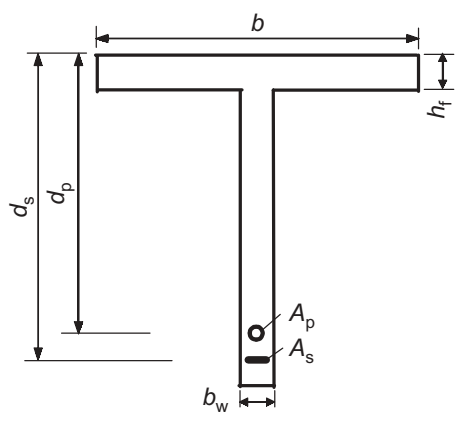

(a)

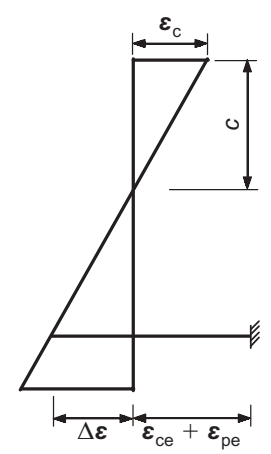

(b)
Fig. 1. Diagrammatic representation of: (a)T-section; and (b) strain distribution

action of a total applied moment $\boldsymbol{M}$, the strain distribution across the depth of the critical section is shown in Fig. 1(b). Let $\Delta \boldsymbol{\varepsilon}$ be the 'fictitious' increase in strain above decompressive strain in concrete at the level of prestressed steel, $\boldsymbol{\varepsilon}_{\mathrm{pe}}$ be the effective prestrain of the prestressed steel, $\boldsymbol{\varepsilon}_{\mathrm{ce}}$ be the precompressive strain in concrete at the level of prestressed steel, and $\boldsymbol{\varepsilon}_{\mathrm{c}}$ be the concrete compressive strain in the top fibre. Therefore the increase in strain $\Delta \boldsymbol{\varepsilon}_{\mathrm{p}}$ in prestressed steel can be worked out through the 'fictitious' strain increment $\Delta \varepsilon$ as

$$
\begin{aligned}
\Delta \boldsymbol{\varepsilon}_{\mathrm{p}} & =\left(\Delta \boldsymbol{\varepsilon}+\boldsymbol{\varepsilon}_{\mathrm{ce}}\right)\left(\frac{L_{\mathrm{e}}}{L}\right) \\
& =\left[\left(\frac{d_{\mathrm{p}}-c}{c}\right) \boldsymbol{\varepsilon}_{\mathrm{c}}+\boldsymbol{\varepsilon}_{\mathrm{ce}}\right]\left(\frac{L_{\mathrm{e}}}{L}\right)
\end{aligned}
$$

where $L$ is the distance between end anchorages. Noting that $L_{\mathrm{e}}=\lambda \times c$, the strain $\varepsilon_{\mathrm{p}}$ in prestressed steel under service load can be written as

$$
\begin{aligned}
\boldsymbol{\varepsilon}_{\mathrm{p}}= & \boldsymbol{\varepsilon}_{\mathrm{pe}}+\Delta \boldsymbol{\varepsilon}_{\mathrm{p}}=\boldsymbol{\varepsilon}_{\mathrm{pe}}+\boldsymbol{\varepsilon}_{\mathrm{ce}}\left(\frac{\lambda c}{L}\right) \\
& +\boldsymbol{\varepsilon}_{\mathrm{c}}\left(\frac{d_{\mathrm{p}}-c}{c}\right)\left(\frac{\lambda c}{L}\right)
\end{aligned}
$$

The unbonded prestressing tendons usually remain elastic and therefore the stress in prestressed steel, $\boldsymbol{f}_{\mathrm{p}}$, can be expressed in terms of the modulus of elasticity of prestressed steel, $E_{\mathrm{p}}$, and the effective prestress, $\boldsymbol{f}_{\mathrm{pe}}$, as

$$
\begin{aligned}
\boldsymbol{f}_{\mathrm{p}} & =E_{\mathrm{p}} \boldsymbol{\varepsilon}_{\mathrm{p}}=E_{\mathrm{p}} \boldsymbol{\varepsilon}_{\mathrm{pe}}+E_{\mathrm{p}} \Delta \boldsymbol{\varepsilon}_{\mathrm{p}} \\
& =\boldsymbol{f}_{\mathrm{pe}}+E_{\mathrm{p}} \boldsymbol{\varepsilon}_{\mathrm{ce}}\left(\frac{\lambda c}{L}\right)+E_{\mathrm{p}} \boldsymbol{\varepsilon}_{\mathrm{c}}\left(d_{\mathrm{p}}-c\right)\left(\frac{\lambda}{L}\right)
\end{aligned}
$$

Generally the value of $\boldsymbol{\varepsilon}_{\mathrm{ce}}$ is negligible compared to the other terms. Thus neglecting $\boldsymbol{\varepsilon}_{\mathrm{ce}}$, equation (5) can be written in terms of the stress increment $\Delta \boldsymbol{f}_{\mathrm{p}}$ caused by external loading as

$$
\boldsymbol{f}_{\mathrm{p}}=\boldsymbol{f}_{\mathrm{pe}}+\Delta \boldsymbol{f}_{\mathrm{p}}=\boldsymbol{f}_{\mathrm{pe}}+E_{\mathrm{p}} \boldsymbol{\varepsilon}_{\mathrm{c}} \lambda\left(d_{\mathrm{p}}-c\right) / L
$$

from which $\lambda$ can be solved as

$$
\lambda=\frac{L\left(\boldsymbol{f}_{\mathrm{p}}-\boldsymbol{f}_{\mathrm{pe}}\right)}{E_{\mathrm{p}} \boldsymbol{\varepsilon}_{\mathrm{c}}\left(d_{\mathrm{p}}-c\right)}
$$

For the beam with cross-section shown in Fig. 1(a), the tension carried by the unbonded tendons $\boldsymbol{T}_{\mathrm{p}}$ and that by the non-prestressed steel $\boldsymbol{T}_{\mathrm{s}}$ are respectively

$$
\begin{gathered}
\boldsymbol{T}_{\mathrm{p}}=A_{\mathrm{p}} \boldsymbol{f}_{\mathrm{p}}=A_{\mathrm{p}} \boldsymbol{f}_{\mathrm{pe}}+A_{\mathrm{p}} E_{\mathrm{p}} \boldsymbol{\varepsilon}_{\mathrm{c}} \lambda\left(d_{\mathrm{p}}-c\right) / L \\
\boldsymbol{T}_{\mathrm{s}}=A_{\mathrm{s}} E_{\mathrm{s}} \boldsymbol{\varepsilon}_{\mathrm{c}}\left(d_{\mathrm{s}}-c\right) / c \leqslant A_{\mathrm{s}} \boldsymbol{f}_{\mathrm{y}}
\end{gathered}
$$

Under service loading when concrete still remains elastic, the compression carried by the flange outside the web $\boldsymbol{C}_{1}$ and that by the web $\boldsymbol{C}_{2}$ are respectively

$$
\begin{gathered}
\boldsymbol{C}_{1}=E_{\mathrm{c}} \boldsymbol{\varepsilon}_{\mathrm{c}} h_{\mathrm{f}}\left(2 c-h_{\mathrm{f}}\right)\left(b-b_{\mathrm{w}}\right) / 2 c \\
=\boldsymbol{f}_{\mathrm{c}} h_{\mathrm{f}}\left(2 c-h_{\mathrm{f}}\right)\left(b-b_{\mathrm{w}}\right) / 2 c \\
\boldsymbol{C}_{2}=E_{\mathrm{c}} \boldsymbol{\varepsilon}_{\mathrm{c}} b_{\mathrm{w}} c / 2=\boldsymbol{f}_{\mathrm{c}} b_{\mathrm{w}} c / 2
\end{gathered}
$$

where $E_{\mathrm{c}}$ is the modulus of elasticity of concrete and $\boldsymbol{f}_{\mathrm{c}}$ is the concrete stress in the top fibre.

The distances $h_{1}$ and $h_{2}$ from the action lines of $\boldsymbol{C}_{1}$ and $\boldsymbol{C}_{2}$ to the top fibre are respectively

$$
\begin{gathered}
h_{1}=\frac{h_{\mathrm{f}}}{3}\left(\frac{3 c-2 h_{\mathrm{f}}}{2 c-h_{\mathrm{f}}}\right) \\
h_{2}=\frac{c}{3}
\end{gathered}
$$

The equilibrium equations of force and moment can be written as

$$
\left\{\begin{array}{l}
\boldsymbol{C}_{1}+\boldsymbol{C}_{2}-\boldsymbol{T}_{\mathrm{p}}-\boldsymbol{T}_{\mathrm{s}}=0 \\
\boldsymbol{C}_{1} h_{2}+\boldsymbol{C}_{2} h_{2}-\boldsymbol{T}_{\mathrm{p}} d_{\mathrm{p}}-\boldsymbol{T}_{\mathrm{s}} d_{\mathrm{s}}=\boldsymbol{M}
\end{array}\right.
$$

For test specimens, the total applied moment $\boldsymbol{M}$ and stress in unbonded tendons $\boldsymbol{f}_{\mathrm{p}}$ are known or measured values. Substituting equations (8)-(13) into equation (14) results in a set of two simultaneous equations with only two unknowns, namely the neutral axis depth $c$ and the concrete strain $\boldsymbol{\varepsilon}_{\mathrm{c}}$ in the top fibre. Once they are solved, the value of $\lambda$ can be obtained from equation (7). The variation of $\lambda$ can therefore be studied in detail.

\section{Numerical analysis of coefficient $\lambda$}

The numerical analysis of coefficient $\lambda$ is based on the incremental deformation method to evaluate the non-linear response of concrete flexural members. ${ }^{15,16}$ Using the stress-strain curves of the constituent materials, an iteration procedure is followed to satisfy compatibility and equilibrium at every loading step in the response history of the member. The present study concentrates on the variation of tendon stress as well as the coefficient $\lambda$ under service load.

The following assumptions are adopted in the analysis: (a) plane sections remain plane after bending; $(b)$ the constitutive relations for prestressed steel, nonprestressed steel and concrete are known; (c) the postcracking tensile strength of concrete is negligible; $(d)$

Magazine of Concrete Research, 2005, 57, No. 4 
the friction along the unbonded tendons is negligible; (e) the member has adequate shear strength to prevent premature shear failure. The ultimate flexural moment is reached either when the moment capacity shows a drop in the loading history analysis, or when the concrete compressive strain in the top fibre of the critical section reaches 0.003. As usual, compressive stresses and strains in concrete are taken as positive and vice versa. For steel, tensile stresses and strains are taken as positive and vice versa. Downward eccentricities of tendons are taken as positive.

The stress-strain relationship for unconfined concrete in compression proposed by Hognestad, ${ }^{17}$ which comprises a parabolic ascending branch and linear descending branch, is used in this study. The stress $\boldsymbol{\sigma}_{\mathrm{c}}$ is related to the strain $\boldsymbol{\varepsilon}_{\mathrm{c}}$ of concrete as

$$
\left\{\begin{array}{r}
\boldsymbol{\sigma}_{\mathrm{c}}=\boldsymbol{f}_{\mathrm{c}}^{\prime}\left[\frac{2 \boldsymbol{\varepsilon}_{\mathrm{c}}}{0.002}-\left(\frac{\boldsymbol{\varepsilon}_{\mathrm{c}}}{0.002}\right)^{2}\right] \\
\text { for } \boldsymbol{\varepsilon}_{\mathrm{c}} \leqslant 0.002 \\
\boldsymbol{\sigma}_{\mathrm{c}}=\boldsymbol{f}_{\mathrm{c}}^{\prime}\left[1-0.15\left(\frac{\boldsymbol{\varepsilon}_{\mathrm{c}}-0.002}{\boldsymbol{\varepsilon}_{\mathrm{cu}}-0.002}\right)\right] \\
\text { for } 0.002<\boldsymbol{\varepsilon}_{\mathrm{c}} \leqslant \boldsymbol{\varepsilon}_{\mathrm{cu}}
\end{array}\right.
$$

where $\boldsymbol{f}_{\mathrm{c}}^{\prime}$ is the cylinder strength of concrete and the ultimate concrete compressive strain in the top fibre is taken as $\boldsymbol{\varepsilon}_{\mathrm{cu}}=0.003$. The stress-strain relationship for concrete in tension is assumed to be linear with a slope equal to the elastic modulus in compression at zero stress. The contribution from concrete in tension after cracking is ignored.

The non-prestressed steel is assumed to be elasticperfectly plastic, and the stress $\boldsymbol{\sigma}_{\mathrm{s}}$ is related to the strain $\boldsymbol{\varepsilon}_{\mathrm{s}}$ as

$$
\begin{cases}\boldsymbol{\sigma}_{\mathrm{s}}=E_{\mathrm{s}} \boldsymbol{\varepsilon}_{\mathrm{s}} & \text { for } \boldsymbol{\varepsilon}_{\mathrm{s}} \leqslant \boldsymbol{f}_{\mathrm{y}} / E_{\mathrm{s}} \\ \boldsymbol{\sigma}_{\mathrm{s}}=\boldsymbol{f}_{\mathrm{y}} & \text { for } \boldsymbol{\varepsilon}_{\mathrm{s}}>\boldsymbol{f}_{\mathrm{y}} / E_{\mathrm{s}}\end{cases}
$$

The stress-strain formula for prestressed steel proposed by Menegotto and Pinto ${ }^{18}$ was shown by Naaman ${ }^{19}$ to be realistic, and it is adopted here. The stress $\sigma_{\mathrm{ps}}$ is related to the strain $\boldsymbol{\varepsilon}_{\mathrm{p}}$ by

$$
\begin{gathered}
\boldsymbol{\sigma}_{\mathrm{ps}}=E_{\mathrm{p}} \boldsymbol{\varepsilon}_{\mathrm{p}}\left(Q+(1-Q) /\left\{1+\left[E_{\mathrm{p}} \boldsymbol{\varepsilon}_{\mathrm{p}} /\left(K f_{\mathrm{py}}\right)\right]^{N}\right\}^{1 / N}\right) \\
Q=\left(\boldsymbol{f}_{\mathrm{pu}}-K f_{\mathrm{py}}\right) /\left(E_{\mathrm{p}} \boldsymbol{\varepsilon}_{\mathrm{pu}}-K \boldsymbol{f}_{\mathrm{py}}\right)
\end{gathered}
$$

where $\boldsymbol{f}_{\mathrm{py}}$ is the yield stress of prestressed steel; $\boldsymbol{f}_{\mathrm{pu}}$ and $\boldsymbol{\varepsilon}_{\mathrm{pu}}$ are the ultimate stress and strain of prestressed steel, respectively; and $N, K$ and $Q$ are empirical parameters whose values are respectively $7 \cdot 344,1.0618$ and 0.01174 for 7 -wire strands of Grade 270 with ultimate tensile strength of $1863 \mathrm{MPa}$.

In the numerical analysis, the UPPC member is divided into $m$ beam elements $(k=1,2, \ldots m)$ with the control element $(k=1)$ located at the critical section. For example, in a simply supported beam with a central-point load, the control element is located at the centre and it is only necessary to consider one half because of symmetry. The concrete strain in the top fibre of the control element is increased in increments to simulate the applied loading. After each increment in concrete strain in the control element, a three-level iteration procedure is carried out to ensure $(a)$ the equilibrium of forces across the depth of all beam elements, $(b)$ the equilibrium between the applied load and the bending moment at each element, and (c) compatibility of the average strain and elongation between the anchorages of the unbonded tendons. Fig. 2 shows a summary of the algorithm particularly in respect of the convergence criterion (c) above. The convergence criteria $(a)$ and $(b)$ can be satisfied at the section considered as follows.

In the first loading step $(i=1)$, the control element $(k=1)$ is loaded to its cracking moment $\boldsymbol{M}_{1, \text { cr }}$ given by

$$
\boldsymbol{M}_{1, \mathrm{cr}}=\boldsymbol{P}_{0} e_{1}+\frac{\boldsymbol{P}_{0} \boldsymbol{I}_{01}}{A_{01} y_{1}^{\mathrm{b}}}+\frac{\boldsymbol{f}_{\mathrm{r}} \boldsymbol{I}_{01}}{y_{1}^{\mathrm{b}}}
$$

with the concrete strain $\boldsymbol{\varepsilon}_{1}^{\mathrm{t}, 1}$ in the top fibre being

$$
\boldsymbol{\varepsilon}_{1}^{\mathrm{t}, 1}=\frac{\boldsymbol{P}_{0}}{E_{\mathrm{c}} A_{01}}-\frac{\boldsymbol{P}_{0} e_{1} y_{1}^{\mathrm{t}}}{E_{\mathrm{c}} \boldsymbol{I}_{01}}+\frac{\boldsymbol{M}_{1, \mathrm{cr}} y_{1}^{\mathrm{t}}}{E_{\mathrm{c}} \boldsymbol{I}_{01}}
$$

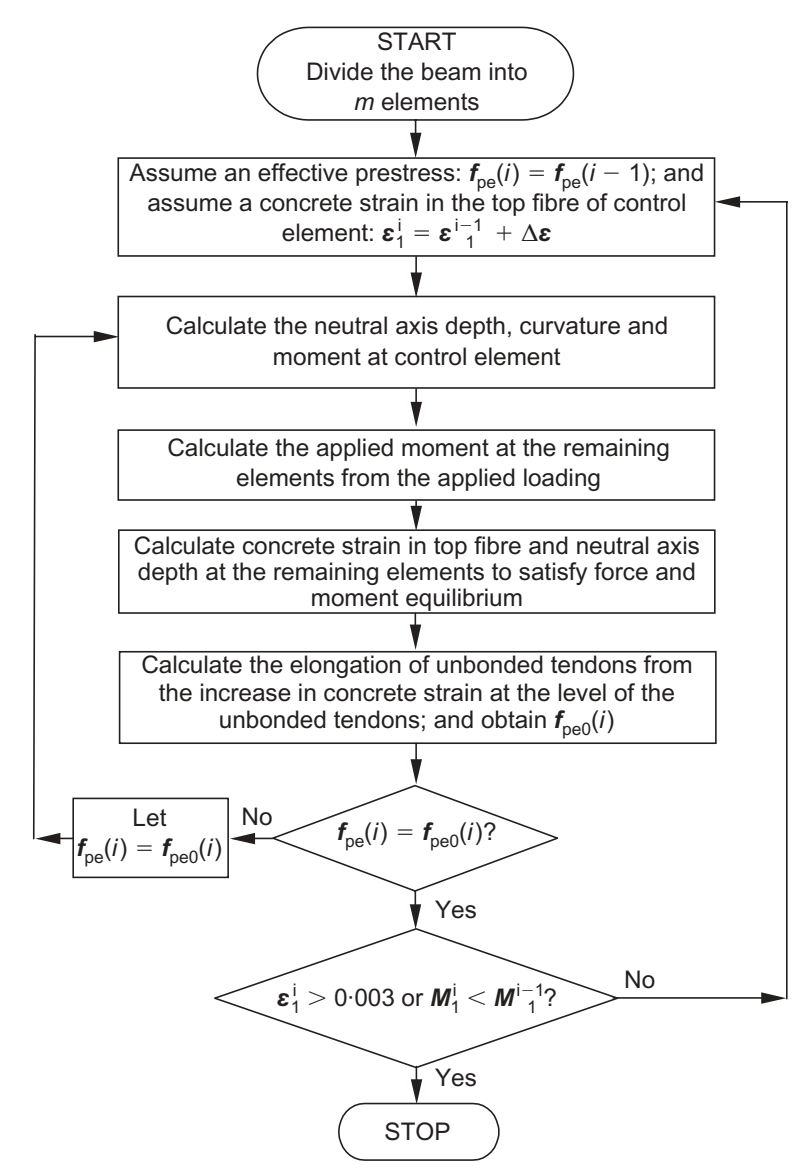

Fig. 2. Flow chart of numerical analysis of unbonded prestressed concrete beams 
where $\boldsymbol{P}_{0}$ is the effective prestressing force before loading; $\boldsymbol{f}_{\mathrm{r}}$ is the modulus of rupture of concrete; $e_{1}$ is the eccentricity of prestressed steel with respect to the centroid of the transformed section of the control element; $A_{01}$ and $\boldsymbol{I}_{01}$ are respectively the area and moment of inertia of the transformed section of the control element; $y_{1}^{\mathrm{b}}$ and $y_{1}^{\mathrm{t}}$ are the distances from the centroidal axis to the bottom and top fibres of the transformed section of the control element, respectively. In the subsequent analysis, the increment of concrete strain in the top fibre of the control element after cracking is set to any small arbitrary value such as $0 \cdot 0001$. Note that the control element should remain cracked hereafter. With the concrete strain in the top fibre known, the neutral axis depth $c_{1}^{\mathrm{i}}$ under loading step $i$ can be obtained by iteration until the force equilibrium is satisfied. The bending moment in the control element $\boldsymbol{M}_{1}^{\mathrm{i}}$ can be worked out accordingly. The applied moments $\boldsymbol{M}_{\mathrm{k}}^{\mathrm{i}}$ $(k=2-m)$ in the remaining elements can be computed from the equilibrium of the beam.

If the applied moment $\boldsymbol{M}_{\mathrm{k}}^{\mathrm{i}}$ is less than or equal to its corresponding cracking moment $\boldsymbol{M}_{k, \mathrm{cr}}$, the concrete strain in the top fibre $\varepsilon_{\mathrm{k}}^{\mathrm{t}, \mathrm{i}}$ and that in the bottom fibre $\boldsymbol{\varepsilon}_{\mathrm{k}}^{\mathrm{b}, \mathrm{i}}$ of element $k$ at loading step $i$ can be computed as

$$
\begin{aligned}
\boldsymbol{\varepsilon}_{\mathrm{k}}^{\mathrm{t}, \mathrm{i}} & =\frac{\boldsymbol{P}_{i}}{E_{\mathrm{c}} A_{0 k}}-\frac{\boldsymbol{P}_{i} e_{k} y_{\mathrm{k}}^{\mathrm{t}}}{E_{\mathrm{c}} \boldsymbol{I}_{0 k}}+\frac{\boldsymbol{M}_{\mathrm{k}}^{\mathrm{i}} y_{\mathrm{k}}^{\mathrm{t}}}{E_{\mathrm{c}} \boldsymbol{I}_{0 k}} \\
\boldsymbol{\varepsilon}_{\mathrm{k}}^{\mathrm{b}, \mathrm{i}} & =\frac{\boldsymbol{P}_{i}}{E_{\mathrm{c}} A_{0 k}}+\frac{\boldsymbol{P}_{i} e_{k} y_{\mathrm{k}}^{\mathrm{b}}}{E_{\mathrm{c}} \boldsymbol{I}_{0 k}}+\frac{\boldsymbol{M}_{\mathrm{k}}^{\mathrm{i}} y_{\mathrm{k}}^{\mathrm{b}}}{E_{\mathrm{c}} \boldsymbol{I}_{0 k}}
\end{aligned}
$$

where $\boldsymbol{P}_{i}$ is the effective prestressing force at step $i ; e_{k}$ is the eccentricity of prestressed steel with respect to the centroid of the transformed section of element $k$; $A_{0 k}$ and $\boldsymbol{I}_{0 k}$ are respectively the area and moment of inertia of the transformed section of element $k$; and $y_{\mathrm{k}}^{\mathrm{b}}$ and $y_{\mathrm{k}}^{\mathrm{t}}$ are the distances from the centroidal axis to the bottom and top fibres of the transformed section of element $k$, respectively. If the applied moment $\boldsymbol{M}_{\mathrm{k}}^{\mathrm{i}}$ exceeds its corresponding cracking moment $\boldsymbol{M}_{k, \mathrm{cr}}$-that is, $\boldsymbol{M}_{k, \text { cr }}<\boldsymbol{M}_{\mathrm{k}}^{\mathrm{i}} \leqslant \boldsymbol{M}_{1}^{\mathrm{i}}$ - the concrete strain in the top fibre $\varepsilon_{\mathrm{k}}^{\mathrm{t}, \mathrm{i}}$ and the neutral axis depth $c_{\mathrm{k}}^{\mathrm{i}}$ can be obtained by iteration until the equilibrium conditions of force and moment are satisfied. Once the tendon stress $\boldsymbol{f}_{\mathrm{pe}}(i)$ at loading step $i$ is available, the coefficient $\lambda_{i}$ at loading step $i$ can be worked out similar to equation (7) as

$$
\lambda_{i}=\frac{L\left(\boldsymbol{f}_{\mathrm{pe}}(i)-\boldsymbol{f}_{\mathrm{pe}}\right)}{E_{\mathrm{p}} \boldsymbol{\varepsilon}_{1}^{\mathrm{i}}\left(d_{\mathrm{p}}-c_{1}^{\mathrm{i}}\right)}
$$

\section{Verification of numerical analysis}

When a UPPC beam is loaded, the load-deflection curve normally exhibits three stages as shown in Fig. 3, namely (a) elastic, $(b)$ cracked-elastic and (c) plastic. The transition from the first to the second stage is caused by the development of cracks at the bottom of the beam, while the transition from the second to the third stage is caused by yielding of the non-prestressed

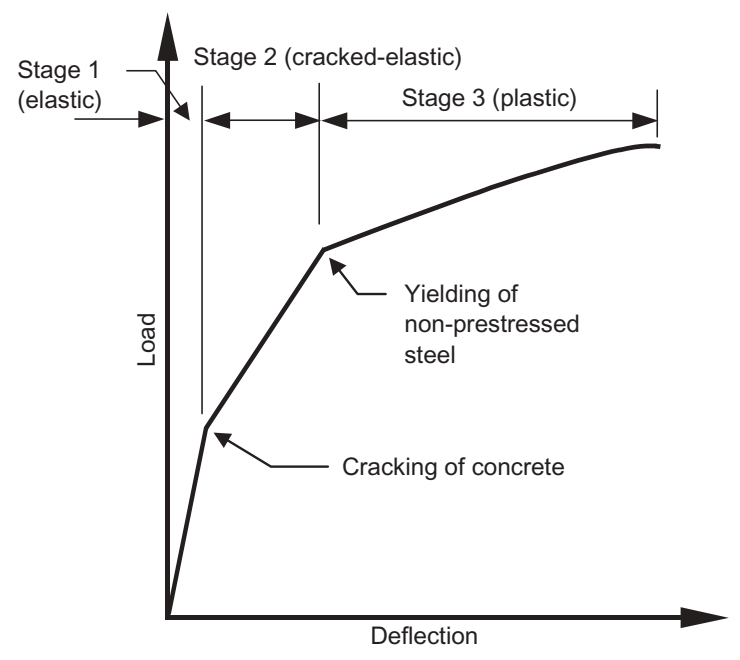

Fig. 3. Simplified load-deflection curve for unbonded partially prestressed concrete beams

steel. The numerical results are then verified by comparison with available experimental results.

In the experiment by $\mathrm{Du}$ and Tao, ${ }^{2} 22$ UPPC beams were tested to investigate the ultimate tendon stress at different levels of reinforcement. All the test beams were $160 \times 280 \mathrm{~mm}(6.4 \times 11 \mathrm{in})$ in cross-section and $4400 \mathrm{~mm}(173.2 \mathrm{in})$ in length, and were tested with third-point loading over a span $L_{\mathrm{n}}$ of $4200 \mathrm{~mm}(165 \cdot 4$ in). The span-depth ratio $L_{\mathrm{n}} / d_{\mathrm{p}}$ was $19 \cdot 1$. The beams were divided into three categories and each beam was designed for the non-prestressed steel to carry about $30 \%, 50 \%$ and $70 \%$ of the total ultimate load. The reinforcement was characterised by the combined reinforcement index $q_{0}$ defined as

$$
q_{0}=\frac{A_{\mathrm{p}} \boldsymbol{f}_{\mathrm{pe}}+A_{\mathrm{s}} \boldsymbol{f}_{\mathrm{y}}}{b d_{\mathrm{p}} \boldsymbol{f}_{\mathrm{c}}^{\prime}}
$$

The index $q_{0}$ fell into three categories: low (beam A$1, q_{0}<0.15$ ), medium (beam A-2, $0.15<q_{0}<0.25$ ) and high (beam A-3, $q_{0}>0 \cdot 25$ ). The numerical and experimental load-deflection curves for three representative beams are plotted in Fig. 4, and they are staggered horizontally for clarity. Similarly, the increase in tendon stress $\Delta \boldsymbol{f}_{\mathrm{p}}$ is plotted against the mid-span deflection for each beam in Fig. 5. It can be seen that the numerical results agree well with the experimental results, showing the three stages clearly. For beams with low and medium levels of combined reinforcement index $q_{0}$, Fig. 5 shows initial straight segments gradually becoming curved with significant deformation in the prestressed steel. However, for the beam with high combined reinforcement index $q_{0}$, the increase in tendon stress remains linear with mid-span deflection until its failure.

In the study by Campbell and Chouinard, ${ }^{3}$ six UPPC beams with section of $160 \times 280 \mathrm{~mm}(6.4 \times 11$ in $)$ and overall length of $3600 \mathrm{~mm}$ (141.7 in) were tested 


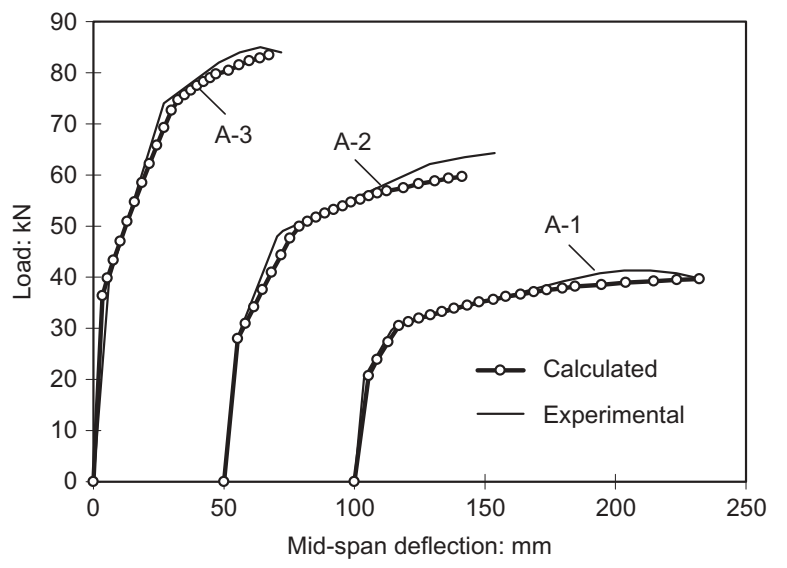

Fig. 4. Relationship between applied load and mid-span deflection for beams from Reference 2

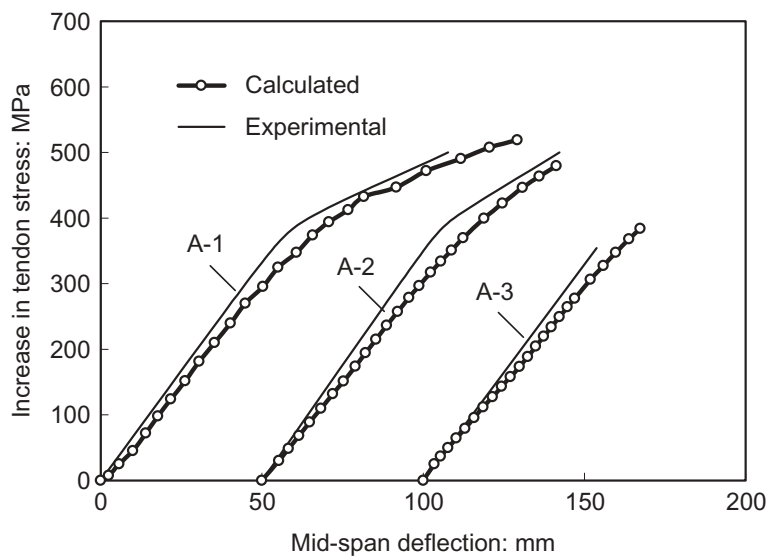

Fig. 5. Relationship between increase in tendon stress and mid-span deflection for beams from Reference 2

under third-point loading. The span length was 3300 $\mathrm{mm}$ (129.9 in), and the span-depth ratio was 15 . The study focused on the influence of non-prestressed steel on the strength of UPPC members. Table 2 shows the experimental and computed results of ultimate tendon stress $\boldsymbol{f}_{\mathrm{ps}}$ and ultimate flexural moment $\boldsymbol{M}_{\mathrm{u}}$. Very good agreement is observed for the six beams tested. The ratio of the measured to computed values of ultimate tendon stress has a mean value of 0.993 and a standard deviation of 0.026 . In the case of ultimate flexural strength, the mean value of the ratio is 1.053 and the standard deviation is $0 \cdot 053$.

\section{Parametric study}

In order to pave the way for a simplified design method, a parametric study is conducted on simply supported UPPC beams with section details as shown in Fig. 6. The amounts of prestressed and nonprestressed steel are so provided that $A_{\mathrm{p}} \boldsymbol{f}_{\mathrm{pe}} /$ $\left(A_{\mathrm{p}} \boldsymbol{f}_{\mathrm{pe}}+A_{\mathrm{s}} \boldsymbol{f}_{\mathrm{y}}\right)=0 \cdot 6$. Emphasis is placed on parameters that may influence the increase in tendon stress $\Delta \boldsymbol{f}_{\mathrm{p}}$ before the yielding of non-prestressed steel and the coefficient $\lambda$ under service load as defined previously. These parameters include the span-depth ratio $L_{\mathrm{n}} / d_{\mathrm{p}}$, combined reinforcement index $q_{0}$ and type of loading. In the parametric study, three different span-depth ratios $L_{\mathrm{n}} / d_{\mathrm{p}}$ are used, namely 10,20 and 30, while three different values of combined reinforcement index $q_{0}$ are adopted, namely $0 \cdot 1,0 \cdot 2$ and $0 \cdot 3$. The types of loading considered include central-point load, third-

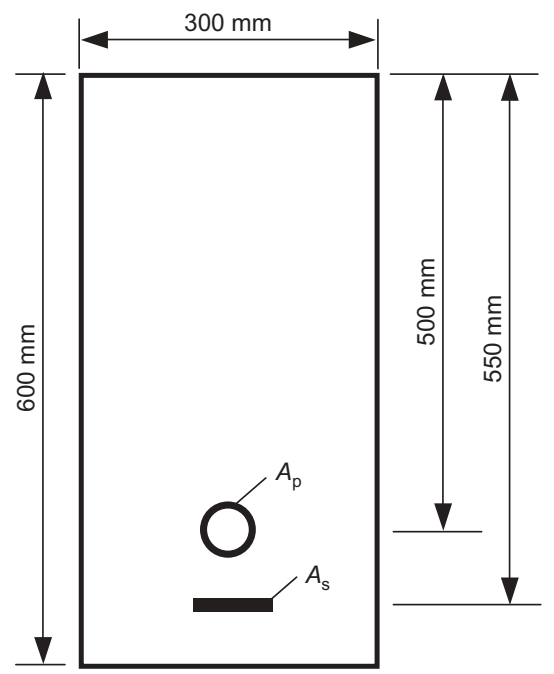

Fig. 6. Cross-sectional dimensions and steel layout of beams for parametric study

Table 2. Comparison of experimental and calculated values of ultimate tendon stress $\boldsymbol{f}_{\mathrm{ps}}$, and ultimate flexural moment $\boldsymbol{M}_{\mathrm{u}}$.

\begin{tabular}{|c|c|c|c|c|c|c|}
\hline Beam No. & $\begin{array}{c}\boldsymbol{f}_{\mathrm{ps}}(\text { exp. }):^{3} \\
\mathrm{MPa} \\
(1)\end{array}$ & $\begin{array}{c}\boldsymbol{f}_{\mathrm{ps}}(\mathrm{cal} .): \\
\mathrm{MPa} \\
(2)\end{array}$ & $(1) /(2)$ & $\begin{array}{c}\boldsymbol{M}_{\mathrm{u}}(\exp .):^{3} \\
\mathrm{kNm} \\
(3)\end{array}$ & $\begin{array}{c}\boldsymbol{M}_{\mathrm{u}}(\mathrm{cal} .) \text { : } \\
\mathrm{kNm} \\
(4)\end{array}$ & $(3) /(4)$ \\
\hline $\begin{array}{l}1 \\
2 \\
3 \\
4 \\
5 \\
6\end{array}$ & $\begin{array}{l}1476 \\
1467 \\
1381 \\
1348 \\
1274 \\
1269\end{array}$ & $\begin{array}{l}1517 \\
1459 \\
1332 \\
1380 \\
1317 \\
1270\end{array}$ & $\begin{array}{l}0.970 \\
1.010 \\
1.040 \\
0.980 \\
0.970 \\
1.000\end{array}$ & $\begin{array}{r}45 \cdot 5 \\
63 \cdot 3 \\
81 \cdot 1 \\
98 \cdot 0 \\
105 \cdot 5 \\
120 \cdot 0\end{array}$ & $\begin{array}{r}46 \cdot 1 \\
59 \cdot 3 \\
72 \cdot 0 \\
91 \cdot 0 \\
103 \cdot 0 \\
116 \cdot 0\end{array}$ & $\begin{array}{l}0.990 \\
1 \cdot 070 \\
1 \cdot 130 \\
1 \cdot 080 \\
1 \cdot 020 \\
1.030\end{array}$ \\
\hline \multicolumn{3}{|c|}{$\begin{array}{l}\text { Average value } \\
\text { Standard deviation }\end{array}$} & $\begin{array}{l}0.993 \\
0.026\end{array}$ & & & $\begin{array}{l}1 \cdot 053 \\
0 \cdot 048\end{array}$ \\
\hline
\end{tabular}


point loading and uniform loading. In this study, the increase in tendon stress under service load $\Delta \boldsymbol{f}_{\mathrm{p}}$ refers to the stress variation from the stage of no loading to that when the non-prestressed steel begins to yield. The average value $\lambda_{\mathrm{av}}$ of the coefficient $\lambda$ is defined as that within the cracked-elastic stage shown in Fig. 3 - that is, the average of all values of $\lambda_{i}$ obtained at each loading step from the cracking of the beam to the yielding of non-prestressed steel.

Numerical analysis indicates that under service load, all else being equal, the span-depth ratio has no significant effect on the increase in tendon stress $\Delta \boldsymbol{f}_{\mathrm{p}}$ before the yielding of non-prestressed steel as shown in Table 3. However Table 4 shows that the average coefficient $\lambda_{\mathrm{av}}$ is roughly proportional to the span-depth ratio of the member. Fig. 7 shows the variation of increase in tendon stress $\Delta \boldsymbol{f}_{\mathrm{p}}$ before the yielding of non-prestressed steel with the combined reinforcement index $q_{0}$ and loading type. It is observed that significantly lower values of $\Delta \boldsymbol{f}_{\mathrm{p}}$ are predicted for the case of central-point load, and so are the values of $\lambda_{\mathrm{av}}$ as listed in Table 4. On the other hand, the results of $\Delta \boldsymbol{f}_{\mathrm{p}}$ and $\lambda_{\mathrm{av}}$ for third-point loading are close to those for uniform loading. These phenomena are caused by the smaller length of equivalent deformation region $L_{\mathrm{e}}$ for the case of central-point load. Fig. 7 also shows that increase in tendon stress $\Delta \boldsymbol{f}_{\mathrm{p}}$ before the yielding of non-prestressed steel increases with the combined rein-

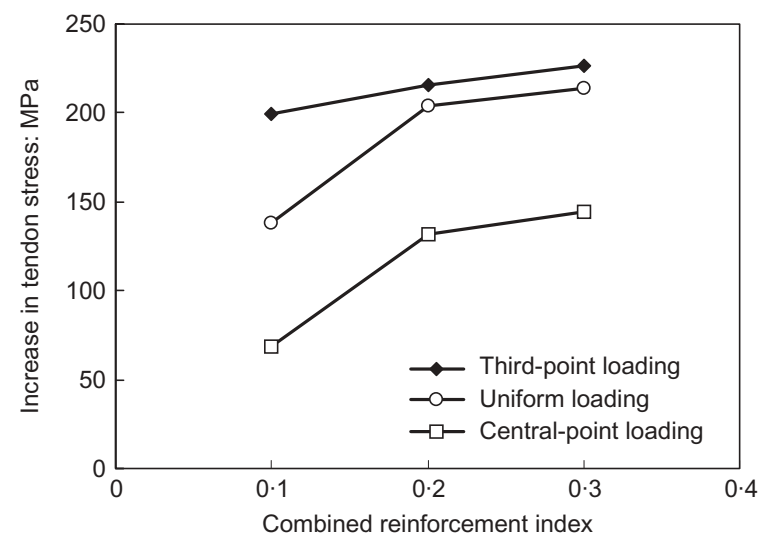

Fig. 7. Variation of increase in tendon stress with combined reinforcement index and loading type

forcement index $q_{0}$. This is because with the increase in steel content, a larger applied moment is necessary to cause yielding in the non-prestressed steel. However it should be noted that, under the same applied loading and therefore moment, the increase in tendon stress should decrease with the increase of $q_{0}$. On the other hand, there are variations in $\lambda_{\mathrm{av}}$ with the combined reinforcement index $q_{0}$ as shown in Table 4 but they are secondary in nature. The proportion of prestressed steel $A_{\mathrm{p}} \boldsymbol{f}_{\mathrm{pe} /}\left(A_{\mathrm{p}} \boldsymbol{f}_{\mathrm{pe}}+A_{\mathrm{s}} \boldsymbol{f}_{\mathrm{y}}\right)$ has been varied from $0 \cdot 3$ to

Table 3. Increase in tendon stress $\Delta \boldsymbol{f}_{\mathrm{p}}(\mathrm{MPa})$ before yielding of non-prestressed steel

\begin{tabular}{l|l|r|r|r}
\hline \multirow{2}{*}{ Span-depth ratio } & Type of loading & \multicolumn{3}{|c}{ Combined reinforcement index $q_{0}$} \\
\cline { 3 - 5 } & & $0 \cdot 1$ & $0 \cdot 2$ & $0 \cdot 3$ \\
\hline \multirow{2}{*}{20} & Central-point load & $68 \cdot 6$ & $131 \cdot 5$ & $144 \cdot 7$ \\
& Third-point loading & $199 \cdot 9$ & $216 \cdot 0$ & $226 \cdot 2$ \\
& Uniform loading & $137 \cdot 9$ & $203 \cdot 6$ & $214 \cdot 3$ \\
& Central-point load & $66 \cdot 2$ & $130 \cdot 4$ & $144 \cdot 2$ \\
30 & Third-point loading & $198 \cdot 9$ & $215 \cdot 3$ & $225 \cdot 6$ \\
& Uniform load & $136 \cdot 9$ & $203 \cdot 4$ & $214 \cdot 0$ \\
& Central-point load & $67 \cdot 1$ & $130 \cdot 6$ & $144 \cdot 4$ \\
& Third-point loading & $198 \cdot 9$ & $215 \cdot 5$ & $225 \cdot 7$ \\
& Uniform load & $137 \cdot 1$ & $203 \cdot 3$ & $214 \cdot 1$ \\
\hline
\end{tabular}

Table 4. Values of $\lambda_{\mathrm{av}}$ at cracked-elastic stage under service load

\begin{tabular}{l|l|r|r|r}
\hline \multirow{2}{*}{ Span-depth ratio } & \multirow{2}{*}{ Type of loading } & \multicolumn{3}{|c}{ Combined reinforcement index $q_{0}$} \\
\cline { 3 - 5 } & & $0 \cdot 1$ & $0 \cdot 2$ & $0 \cdot 3$ \\
\hline \multirow{2}{*}{20} & Central-point load & $6 \cdot 2$ & $8 \cdot 5$ & $8 \cdot 7$ \\
& Third-point loading & $14 \cdot 8$ & $14 \cdot 3$ & $14 \cdot 8$ \\
& Uniform loading & $11 \cdot 4$ & $13 \cdot 5$ & $12 \cdot 9$ \\
& Central-point load & $12 \cdot 1$ & $17 \cdot 0$ & $17 \cdot 4$ \\
& Third-point loading & $29 \cdot 6$ & $28 \cdot 5$ & $26 \cdot 5$ \\
& Uniform loading & $22 \cdot 8$ & $27 \cdot 1$ & $25 \cdot 8$ \\
& Central-point load & $18 \cdot 2$ & $25 \cdot 5$ & $26 \cdot 1$ \\
& Third-point loading & $44 \cdot 3$ & $42 \cdot 7$ & $39 \cdot 7$ \\
& Uniform loading & $34 \cdot 1$ & $40 \cdot 6$ & $38 \cdot 8$ \\
\hline
\end{tabular}


0.7 while keeping the index $q_{0}$ unchanged, but the corresponding values of $\lambda_{\mathrm{av}}$ are reasonably stable.

\section{Proposed design method for calculation of service stresses}

A simplified design method for calculation of service stresses before the yielding of non-prestressed steel is then proposed. It is observed from the numerical analysis that, for a given beam, the variation of $\lambda$ is not large before the yielding of non-prestressed steel, as can be seen in Fig. 8 for a beam with span-depth ratio of 10 and $q_{0}$ of $0 \cdot 2$. Fig. 8 shows that after the yielding of non-prestressed steel, the value of $\lambda$ for the beams loaded with central-point load or uniform load decreases with the increase of concrete compressive strain in the top fibre. However it has no effect on the calculation of service stresses, which is the main concern of the present paper. The major factors governing the magnitude of $\lambda_{\mathrm{av}}$ are the span-depth ratio and loading type, while the combined reinforcement index $q_{0}$ has much less effect. Noting that the value of $\lambda_{\mathrm{av}}$ is roughly proportional to the span-depth ratio and taking members with span-depth ratio $L_{\mathrm{n}} / d_{\mathrm{p}}$ of 10 as reference, it is reasonable in practical analysis of UPPC beams under service load to take $\lambda$ as

$$
\lambda=\left(L_{\mathrm{n}} / d_{\mathrm{p}}\right) \lambda_{10} / 10
$$

for which it is reasonable to take $\lambda_{10}=5$ for centralpoint load and $\lambda_{10}=10$ for third-point loading and uniform load. Once $\lambda$ is determined, the stress analysis after cracking in a UPPC beam can be treated in a similar way as a bonded partially prestressed beam.

The strains and stresses of the components can be worked out by considering the section as an equivalent reinforced concrete section subjected to an eccentric compression force. ${ }^{6}$ Under the effective prestressing force $\boldsymbol{P}_{0}$ alone, the UPPC beam is compressed. The fictitious scenario of decompression of the concrete, at which there is zero concrete strain through the entire depth, can be achieved by pulling the prestressed steel

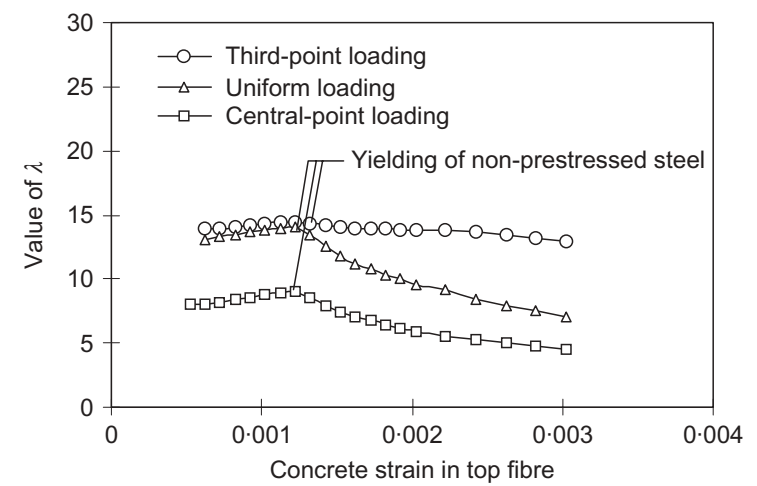

Fig. 8. Variation of $\lambda$ with concrete strain in top fibre (spandepth ratio $=10 ; q_{0}=0 \cdot 2$ )

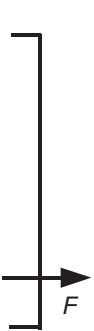

(a)

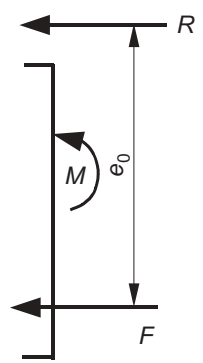

(b)

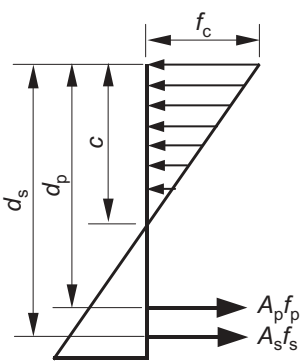

(c)
Fig. 9. Basis for analysis of cracked cross-section; ${ }^{8}$ (a) decompression; (b) forces on cracked section; (c) resulting stresses

with a pair of fictitious forces $\boldsymbol{F}$ shown in Fig. 9(a) and given by

$$
\boldsymbol{F}=\boldsymbol{P}_{0}+E_{\mathrm{p}} A_{\mathrm{p}} \Omega\left(\frac{\boldsymbol{P}_{0}}{E_{\mathrm{c}} A_{0}}+\frac{\boldsymbol{P}_{0} e^{2}}{E_{\mathrm{c}} \boldsymbol{I}_{0}}\right)
$$

where $\Omega$ is the bond reduction coefficient in Table $1, e$ is the eccentricity of prestressed steel with respect to the centroid of the transformed section, and $A_{0}$ and $\boldsymbol{I}_{0}$ are the area and moment of inertia of the transformed section respectively. Note that the second term is the extra amount over the effective prestressing force $\boldsymbol{P}_{0}$ to decompress the concrete. The effect of this fictitious decompression can be cancelled by applying an equal and opposite force $\boldsymbol{F}$ as shown in Fig. 9(b). This force, together with the applied moment $\boldsymbol{M}$ due to dead and imposed loads, can be represented by a resultant force $\boldsymbol{R}=\boldsymbol{F}$ applied at a distance $e_{0}=\boldsymbol{M} / \boldsymbol{R}$ above the centroid of the prestressed steel.

Taking a T-section as an example, the compression carried by the flange outside the web $\boldsymbol{C}_{1}$ and that by the web $\boldsymbol{C}_{2}$ and their corresponding distances $h_{1}$ and $h_{2}$ from the top fibre are given by equations (10) to (13). The increases in tension in prestressed steel $\Delta \boldsymbol{T}_{\mathrm{p}}$ and the tension in non-prestressed steel $\boldsymbol{T}_{\mathrm{s}}$ can be written similarly in terms of the concrete stress in the top fibre $\boldsymbol{f}_{\mathrm{c}}$ as

$$
\begin{aligned}
\Delta \boldsymbol{T}_{\mathrm{p}} & =A_{\mathrm{p}} E_{\mathrm{p}} \boldsymbol{f}_{\mathrm{c}} \lambda\left(d_{\mathrm{p}}-c\right) / E_{\mathrm{c}} L \\
\boldsymbol{T}_{\mathrm{s}} & =A_{\mathrm{s}} E_{\mathrm{s}} \boldsymbol{f}_{\mathrm{c}}\left(d_{\mathrm{s}}-c\right) / E_{\mathrm{c}} c
\end{aligned}
$$

From force equilibrium, the resultant force $\boldsymbol{R}$ can be written as

$$
\boldsymbol{R}=\boldsymbol{C}_{1}+\boldsymbol{C}_{2}-\Delta \boldsymbol{T}_{\mathrm{p}}-\boldsymbol{T}_{\mathrm{s}}
$$

The concrete stress in the top fibre $\boldsymbol{f}_{\mathrm{c}}$ can thus be obtained as

$$
\begin{aligned}
\boldsymbol{f}_{\mathrm{c}}= & 2 R c /\left[b_{\mathrm{w}} c^{2}+\left(2 c-h_{\mathrm{f}}\right)\left(b-b_{\mathrm{w}}\right) h_{\mathrm{f}}\right. \\
& \left.-\frac{2 A_{\mathrm{s}} E_{\mathrm{s}}\left(d_{\mathrm{s}}-c\right)}{E_{\mathrm{c}}}-\frac{2 A_{\mathrm{p}} E_{\mathrm{p}} \lambda\left(d_{\mathrm{p}}-c\right) c}{E_{\mathrm{c}} L}\right]
\end{aligned}
$$

Taking moment about the resultant force $\boldsymbol{R}$ results in a cubic equation for neutral axis depth $c$, that is 
Au et al.

$$
c^{3}+g_{1} c^{2}+g_{2} c+g_{3}=0
$$

where the coefficients are given as

$$
\begin{gathered}
g_{1}=3\left(e_{0}-d_{\mathrm{p}}\right)+\frac{6 \lambda A_{\mathrm{p}} E_{\mathrm{p}} \mathrm{e}_{0}}{E_{\mathrm{c}} L b_{\mathrm{w}}} \\
g_{2}=\frac{6}{b_{\mathrm{w}}}\left[h_{\mathrm{f}}\left(b-b_{\mathrm{w}}\right)\left(e_{0}-d_{\mathrm{p}}+0 \cdot 5 h_{\mathrm{f}}\right)\right. \\
\left.-\frac{\lambda A_{\mathrm{p}} E_{\mathrm{p}} e_{0} d_{\mathrm{p}}}{E_{\mathrm{p}} L}+\frac{A_{\mathrm{s}} E_{\mathrm{s}}\left(e_{0}-d_{\mathrm{p}}+d_{\mathrm{s}}\right)}{E_{\mathrm{c}}}\right] \\
g_{3}=-\frac{6}{b_{\mathrm{w}}}\left[\frac{h_{\mathrm{f}}^{2}}{2}\left(b-b_{\mathrm{w}}\right)\left(e_{0}-d_{\mathrm{p}}+\frac{2 h_{\mathrm{f}}}{3}\right)\right. \\
\left.+\frac{E_{\mathrm{s}} A_{\mathrm{s}} d_{\mathrm{s}}}{E_{\mathrm{c}}}\left(e_{0}-d_{\mathrm{p}}+d_{\mathrm{s}}\right)\right]
\end{gathered}
$$

The neutral axis depth $c$ can be solved from equation (29a) by iterations. The depth of the centroid of the cracked section below the top fibre $\bar{y}$ is given by

$$
\bar{y}=\frac{\left(b-b_{\mathrm{w}}\right) h_{\mathrm{f}}^{2} / 2+b_{\mathrm{w}} c^{2} / 2+E_{\mathrm{s}} A_{\mathrm{s}} d_{\mathrm{s}} / E_{\mathrm{c}}}{\left(b-b_{\mathrm{w}}\right) h_{\mathrm{f}}+b_{\mathrm{w}} c+E_{\mathrm{s}} A_{\mathrm{s}} / E_{\mathrm{c}}}
$$

while the moment of inertia of the cracked section $\boldsymbol{I}_{\mathrm{cr}}$ is

$$
\begin{aligned}
\boldsymbol{I}_{\mathrm{cr}}= & \frac{b_{\mathrm{w}} \bar{y}^{3}}{3}+\frac{b_{\mathrm{w}}(c-\bar{y})^{3}}{3}+h_{\mathrm{f}}\left(b-b_{\mathrm{w}}\right)\left(\bar{y}-0 \cdot 5 h_{\mathrm{f}}\right)^{2} \\
& +\frac{\left(b-b_{\mathrm{w}}\right) h_{\mathrm{f}}^{3}}{12}+\frac{E_{\mathrm{s}} A_{\mathrm{s}}\left(d_{\mathrm{s}}-\bar{y}\right)^{2}}{E_{\mathrm{c}}}
\end{aligned}
$$

The stresses of various components can then be worked out accordingly.

\section{Comparison of theoretical results with test results}

To demonstrate the validity of the proposed design method, the computed results are compared with available experimental results. Fig. 10 shows the relation-

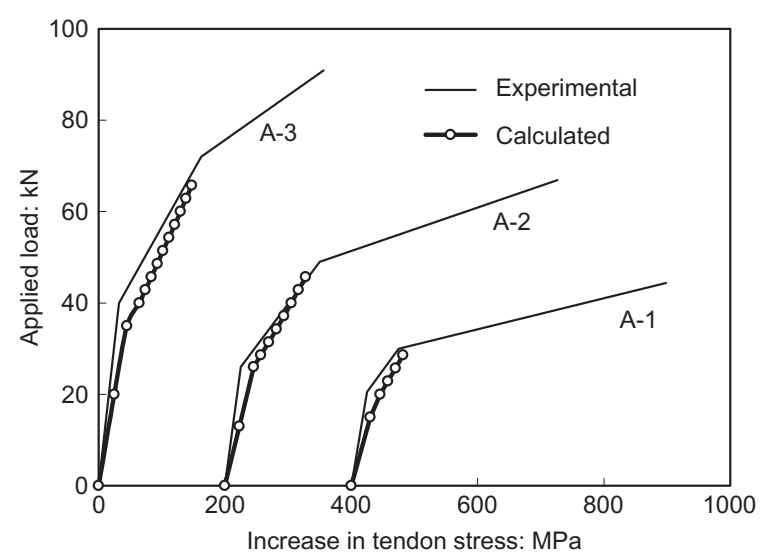

Fig. 10. Relationship between applied load and increase in tendon stress for beams from Reference 2 ship between the total applied load and the increase in tendon stress $\Delta \boldsymbol{f}_{\mathrm{p}}$ for beams A-1, A-2 and A-3 in the experiments of $\mathrm{Du}$ and Tao. ${ }^{2}$ As before, the curves are staggered horizontally for clarity. Good agreement between the calculated and experimental results is observed.

In the study by Harajli and Kanj, ${ }^{5}$ a total of 26 simply supported beam specimens with rectangular cross-section were tested. The main input parameters included three different amounts of prestressed steel, two different ratios of amounts of non-prestressed to prestressed steel, and three different member spandepth ratios. For each set of input parameters, one beam was tested under a central-point load, while another was tested under third-point loading. Fig. 11 shows the relationship between the applied mid-span bending moment and the increase in tendon stress $\Delta \boldsymbol{f}_{\mathrm{p}}$ for four specimens, in which PP3R3-0 and PP2R3-0 were under central-point load, while PP3R-3 and PP2R3-3 were under third-point loading. It can be seen that the proposed method gives satisfactory predictions of service stresses for different loading types.

\section{Conclusions}

This paper has extended the capability of Pannell's coefficient $\lambda$, which is the ratio of length of equivalent deformation region $L_{\mathrm{e}}$ to the neutral axis depth $c$ at critical section, to the cracked section analysis of unbonded partially prestressed concrete members under service load. The variations of tendon stress and the coefficient $\lambda$ under service load have been studied by numerical analysis. The following conclusions have been drawn.

(a) Numerical analysis indicates that under service load, all else being equal, the span-depth ratio has no significant effect on the increase in tendon

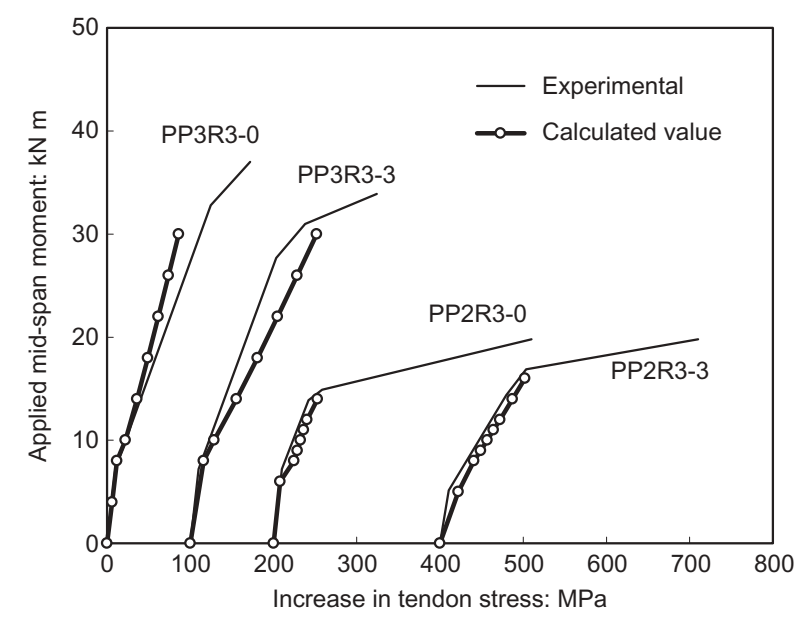

Fig. 11. Relationship between applied moment and increase in tendon stress for beams from Reference 5

Magazine of Concrete Research, 2005, 57, No. 4 
stress $\Delta \boldsymbol{f}_{\mathrm{p}}$. The average value $\lambda_{\mathrm{av}}$ of the coefficient $\lambda$ is almost proportional to the span-depth ratio of a member.

(b) Significantly lower values of $\Delta \boldsymbol{f}_{\mathrm{p}}$ and $\lambda_{\mathrm{av}}$ are predicted for the beams subjected to central-point load, as opposed to similar beams subjected to third-point loading or uniform loading. On the other hand, the values of $\Delta \boldsymbol{f}_{\mathrm{p}}$ and $\lambda_{\mathrm{av}}$ for thirdpoint loading are close to those for uniform loading.

(c) Under service load, $\lambda$ is not sensitive to the variation of the combined reinforcement index $q_{0}$. After cracking of the beam and until the yielding of nonprestressed steel, the value of $\lambda$ is fairly stable.

(d) In practical stress analysis of cracked sections of unbonded partially prestressed concrete beams, $\lambda$ can be approximated by equation (23).

(e) A method has been proposed for the calculation of stresses in concrete, prestressed steel and nonprestressed steel in unbonded partially prestressed beams after cracking, permitting a more satisfactory assessment of serviceability.

\section{Acknowledgements}

The work described in this paper was partially supported by the Internal Award for CAS Membership of The University of Hong Kong. The work described in this paper has been partly supported by the Research Grants Council of the Hong Kong Special Administrative Region, China (RGC Project No. HKU 7101/04E).

\section{References}

1. American Concrete Institute. State-of-the-art Report on Partially Prestressed Concrete (ACI 423.5R-99). JOINT ACIASCE COMMITTE 423, Farmington Hills, Michigan, 2000, 37 pp.

2. Du G. C. and TAo X. K. Ultimate stress of unbonded tendons in partially prestressed concrete beams. PCI Journal, 1985, 30, No. 6, 72-91.

3. Campbell T. I. and Chouinard K. L. Influence of non-prestressed reinforcement on the strength of unbonded partially prestressed concrete members. ACI Structural Journal, 1991, 88, No. 5, 546-551.

4. HaraJli M. H. and Kanj M. Y. Ultimate flexural strength of concrete members prestressed with unbonded tendons. ACI Structural Journal, 1991, 88, No. 6, 663-673.

5. Harajli M. H. and Kanj M. Y. Service load behavior of concrete members prestressed with unbonded tendons. Journal of Structural Engineering, ASCE, 1992, 118, No. 9, 2569-2589.

6. Chakrabarti P. R., Whang T. P., Brown W., Arsad K. M. and Amezeua E. Unbonded post-tensioned tendons and partially prestressed beams. ACI Structural Journal, 1994, 91, No. 5, 616-625.

7. Au F. T. K. and Du J. S. Partially prestressed concrete. Progress in Structural Engineering and Materials, 2004, 6, No. 2, $127-135$.

8. Nilson A. H. Design of Prestressed Concrete, 2nd edn. Wiley, New York, 1987, 592 pp.

9. Balaguru P. N. Increase of stress in unbonded tendons in prestressed concrete beams and slabs. Canadian Journal of Civil Engineering, 1981, 8, No. 2, 262-268.

10. NaAman A. E. and Alkhairi F. M. Stress at ultimate in unbonded post-tensioning tendons: part 2-proposed methodology. ACI Structural Journal, 1991, 88, No. 6, 683-692.

11. Pannell F. N. The ultimate moment of resistance of unbonded prestressed concrete beams. Magazine of Concrete Research, 1969, 21, No. 66, 43-54.

12. British Standards Institution. Structural Use of Concrete. BSI, London, 1985, BS 8110 - Parts 1, 2 and 3.

13. Canadian Standards Association. Design of Concrete Structures. CSA, Rexdale, Ontario, 1994, A23·3-94.

14. AU F. T. K. and DU J. S. Prediction of ultimate stress in unbonded prestressing tendons. Magazine of Concrete Research, 2004, 56, No. 1, 1-11.

15. Alkhairi F. M. and NaAman A. E. Analysis of beams prestressed with unbonded internal or external tendons. Journal of Structural Engineering, ASCE, 1993, 119, No. 9, 2680-2700.

16. Harajli M. H., Khairallah N. and Nassif H. Externally prestressed members: evaluation of second-order effects. Journal of Structural Engineering, ASCE, 1999, 125, No. 10, 11511161 .

17. Hognestad E. A study of combined bending and axial load in reinforced concrete members. Bulletin No. 399, University of Illinois Engineering Experiment Station, Urbana, IL, 1951.

18. Menegotto M. and Pinto P. E. Method of analysis for cyclically loaded RC plane frames, including changes in geometry and non-elastic behavior or elements under combined normal force and bending. Proceedings of IABSE Symposium on Resistance and Ultimate Deformability of Structures Acted on by Well-defined Repeated Loads, Lisbon, 1973, pp. 15-22.

19. NaAman A. E. Partially prestressed concrete: review and recommendations. PCI Journal, 1985, 30, No. 6, 31-71.

Discussion contributions on this paper should reach the editor by 1 November 2005 